\title{
Meningitis aséptica por varicela zóster sin rash vesicular previo en paciente VIH positivo. Presentación de caso
}

\author{
Nathalia Buitrago-Gómez* \\ José Bacca-Arcos** \\ Lina María Villa-Sánchez ${ }^{* * *}$ \\ Jose Mauricio Cárdenas-Prieto****
}

\begin{abstract}
*Médica general. Residente III año de Medicina Interna. Universidad Libre. Cali. Valle. Colombia. **Médico general. Clínica Nueva Rafael Uribe. Cali. Valle. Colombia.

***Médica internista infectóloga. Clínica Nueva Rafael Uribe. Cali. Valle. Colombia.

****Neurólogo. Clínica Nueva Rafael Uribe. Cali. Valle. Colombia.

Correspondencia: Nathalia Buitrago Gómez. Teléfono celular: +57 3185173090. Dirección: Calle 44\# 23a-30, barrio Nuevo Príncipe. Tuluá, Valle. Colombia.Correo electrónico: natybugo@gmail.com
\end{abstract}

\section{Resumen}

Un cuadro de meningitis aséptica, en el contexto de un paciente inmunosuprimido con diagnóstico de infección por Virus de Inmunodeficiencia Humana (VIH), debe llevar a pensar en múltiples diagnósticos diferenciales. Entre estos, se incluye el virus varicela zóster (VVZ) como uno de los principales agentes causales de meningitis a líquido cefalorraquídeo claro. Su reactivación da lugar a múltiples manifestaciones neurológicas potencialmente mortales en las que se consideraba al rash vesicular, o exantema pápulo/vesículo/ costroso como un signo fundamental para su diagnóstico. No obstante, las lesiones cutáneas están ausentes en más de un tercio de los pacientes con compromiso del sistema nervioso central. A continuación, se presenta el caso de un paciente con infección por VIH que presenta cefalea más fiebre, con hallazgos en líquido cefalorraquídeo de pleocitosis neutrofílica y una prueba molecular confirmatoria para virus varicela zóster, en ausencia de rash vesicular previo que guiara hacia este diagnóstico. MÉD.UIS.2021;34(1): 91-9.

Palabras clave: Meningitis Aséptica. Serodiagnóstico de VIH. Inmunosupresión. Infección por el Virus de la Varicela-Zóster.

\section{Varicella Zoster aseptic meningitis without previous vesicular rash in VIH positive patient. Case report}

\begin{abstract}
The clinical presentation of aseptic meningitis in the context of an immunosuppressed patient with a diagnosis of Human Immunodeficiency Virus (HIV) infection, should lead us to consider multiple differential diagnoses. Among these, the Varicella Zoster Virus (VZV) has been found as one of the main causative agents of clear cerebrospinal fluid meningitis. Its reactivation gives rise to multiple life-threatening neurological manifestations in which vesicular rash, or papule / vesicular / crusted rash was considered a fundamental sign for its diagnosis. However, skin lesions are absent in more than a third of patients with central nervous system involvement. Herein, we report a case of an HIV-infected patient with headache, fever and neutrophilic pleocytosis with FilmArray that confirms Varicella Zoster virus infection in an immunocompromised patient in the absence of vesicular rash. MÉD.UIS.2021;34(1): 91-9.
\end{abstract}

Keywords: Aseptic Meningitis. Varicella Zoster Virus Infection. HIV Serodiagnosis. Immunosuppression.

Artículo recibido el 3 de agosto de 2020 y aceptado para publicación el 22 de enero de 2021 . 
¿Cómo citar este artículo? Buitrago-Gómez N, Bacca-Arcos J, Villa-Sánchez LM, Cárdenas-Prieto JM. Meningitis aséptica por varicela zóster sin rash vesicular previo en paciente VIH positivo. Presentación de caso. MÉD.UIS.2021;34(1):91-9. doi: 10.18273/revmed.v34n1-2021009

\section{Introducción}

La meningitis aséptica tiene una presentación clínica similar a la de la meningitis bacteriana, con síntomas tales como fiebre, cefalea, deterioro del estado de conciencia, rigidez de nuca y fotofobia'. Cabe anotar que las manifestaciones clínicas varían de acuerdo al tipo de virus, la edad y el estado inmune del hospedero, con una severidad mayor en los neonatos, personas inmunodeficientes y con diagnóstico de agammaglobulinemia ${ }^{2}$. Se ha definido como un síndrome adquirido en la comunidad, con líquido cefalorraquídeo (LCR) claro, pleocitosis a predominio mononuclear, cultivo negativo, tinciones de Gram, Ziehl-Neelsen y tinta china negativas, y sin un foco parameníngeo ${ }^{3}$. Muchos virus pueden causar meningitis, especialmente enterovirus, herpesvirus y en algunas partes del mundo, arbovirus. Su incidencia se ha estimado entre 0.26 y 17 casos por 100000 habitantes dependiendo de la edad o el estado de vacunación de la población'.

Los virus herpes más frecuentemente detectados son el herpes simplex (VHS) tipo 2 y el virus varicela zóster (VVZ). El VVZ es un alfaherpesvirus exclusivamente neurotrópico humano que primariamente causa varicela (manifestaciones cutáneas), y posteriormente se aloja de forma latente en los ganglios de los nervios craneales, de la raíz dorsal y autonómicos a lo largo del tubo neural ${ }^{4}$. La reactivación del VVZ en sistema nervioso central está asociada con una variedad de complicaciones potencialmente mortales, tanto en el individuo inmunocomprometido como inmunocompetentes. Su reactivación es una de las enfermedades infecciosas neurológicas más comunes y el segundo virus que causa más frecuentemente encefalitis o meningitis ${ }^{6-7}$. La incidencia anual de infección por VVZ es de 3 casos por 100000 habitantes $^{8}$ y cuando se revisa entre todos los pacientes con meningitis, 9.8\% de los casos fueron por VVZ9. En Colombia no existen muchos estudios epidemiológicos en este campo, históricamente, en Antioquia en el año 2004 se registró un brote de meningitis viral con 263 casos reportados ${ }^{2}$. Asimismo, en el departamento de Córdoba, se estudiaron serológicamente 503 muestras hospitalarias de casos agudos ingresados por meningitis entre 2002 y 2004. Se estimó una tasa de incidencia de 3.8 por 100 000, con Streptococcus Pneumoniae como el principal agente causal en un $25.4 \%$ de $\operatorname{casos}^{10-11}$.

Los factores de riesgo para meningitis incluyen trastornos crónicos (enfermedad renal, insuficiencia adrenal, fibrosis quística), edades extremas, falta de vacunación, estado de inmunocompromiso (iatrogénico, receptores de trasplantes, inmunodeficiencias congénitas, $\mathrm{VIH}$ ), vivir en condiciones de hacinamiento, exposiciones como viajes a áreas endémicas o vectores, abuso de alcohol, presencia de shunt ventriculoperitoneal, endocarditis bacteriana, malignidad, usuario de drogas endovenosas, anemia de células falciformes, esplenectomía ${ }^{12}$. Referente a los factores de riesgo para la infección por VVZ, se han encontrado la historia familiar, un episodio previo de infección por VVZ, pérdida de peso reciente, depresión y trastornos del sueño, siendo la inmunosupresión por $\mathrm{VIH}$, la malignidad y edad avanzada como los factores con más peso para desarrollar esta infección (RR: 3.22, 2.17 y 1.65 respectivamente). Se encontró que la raza negra tuvo tasas más bajas del desarrollo de herpes zóster ${ }^{13-14}$. En particular, se ha observado que la distribución craneocervical y el género masculino están asociados con un mayor riesgo de desarrollo de meningitis aséptica en contexto de infección por $\mathrm{VVZ}^{15}$.

Aunque la principal causa son los virus, muchas otras etiologías tanto infecciosas como no infecciosas, pueden ser responsables de esta entidad ${ }^{16}$. La mayoría de los casos de meningitis aséptica adquirida en la comunidad en el paciente inmunocompetente son el resultado de virus, principalmente enterovirus, que constituyen más del $60 \%$, seguido del VHS tipo 2. Menos comúnmente, se encuentran los arbovirus, adenovirus, VHS tipo 1, Epstein-Barr, citomegalovirus y el VVZ. Aparte de los virus, se encuentran también las bacterias, tales como leptospira, Borrelia burgdorferi, Treponema pallidum, Mycobacterium tuberculosis, Brucela, infecciones fúngicas por Cryptococcus, Coccidioides e Histoplasma, y los parásitos como Trypanosoma cruzi, Toxoplasma gondii y Acanthoamoeba ${ }^{17}$. 
La meningitis es una complicación rara del VVZ, con una incidencia de solo $0.5 \%$ con un aumento progresivo con la edad, pasando a 2.5 casos/1000 entre 21 y 50 años versus 10.1 casos/1000 en los mayores de 80 años. Asimismo, sucede con la infección por VIH, en donde la incidencia aumenta exponencialmente a 29.4 casos/1000 personas-año en comparación con los 2 casos/100o personas-año en los VIH negativos ${ }^{18}$. Adicionalmente, en este grupo de pacientes implica una alta morbilidad y mortalidad ${ }^{19}$.

Referente al mecanismo fisiopatológico, se ha considerado que las dos rutas básicas para el acceso de los virus al Sistema Nervioso Central (SNC), son la hematógena (enterovirus) o la neuronal (VHS) ${ }^{17}$. Adicionalmente, muchos otros mecanismos incluyen la infección directa de los plexos coroideos, o el transporte de células hematopoyéticas infectadas directamente al SNC por flujo sanguíneo directo o tejido linfoide ${ }^{16}$.

La meningitis aséptica abarca un diagnóstico diferencial amplio. Entre los principales virus predomina la cefalea, mientras que la fotofobia, rigidez de nuca, náuseas o vómitos son predominantes en enterovirus y VHS al compararlo con VVZ1. Algunas de las claves que también pueden guiar hacia una etiología específica viral es la presencia de herpes genital, el cual está presente en un $85 \%$ de los pacientes con meningitis. ${ }^{20}$ Por su parte, las causas no infecciosas se han dividido en tres grupos principales:

1. Enfermedades sistémicas con afectación meníngea, entre las que se incluyen la sarcoidosis, que pese a tener pleocitosis linfocitaria, en general cursa con normoglucorraquia, tiene predominancia femenina y clínicamente suele cursar con alteración a nivel de nervios craneales; la enfermedad de Behçet, que se diferencia por la presencia de meningitis neutrofílica, otras manifestaciones sistémicas como úlceras orales o genitales, lesiones de la piel y trastornos a nivel de los ojos; síndrome de Sjögren que típicamente se da en mayores de 40 años y se encuentra en el $90 \%$ de mujeres con síndrome sicca y combinación de polineuropatía y parálisis de nervios craneales; lupus eritematoso sistémico, que inicia usualmente antes de los 40 , tiene predominancia femenina, la clínica predominante es neuropsiquiátrica, extraneurológica y la pleocitosis es muy leve usualmente con $<50$ células $/ \mathrm{mm}^{3}$; y granulomatosis con poliangitis, que suele presentar otras manifestaciones especialmente a nivel del tracto respiratorio ${ }^{21}$.

2. Inducida por medicamentos, especialmente antiinflamatorios no esteroideos, antibióticos (sulfamidas, penicilinas), inmunoglobulina endovenosa, y anticuerpos monoclonales. En este grupo, su principal diagnóstico diferencial es la meningitis bacteriana, debido a niveles de proteína moderadamente elevados y pleocitosis neutrofílica ${ }^{21}$.

3. Meningitis neoplásicas, ya sea relacionada con tumores sólidos metastásicos (cáncer de mama, cáncer de pulmón, melanoma) o hematológica (leucemia, linfoma). Su gran diferencia radica en la lesión neurológica multifocal rápidamente progresiva con déficit motor y sensorial, incluyendo alteración a nivel de los nervios craneales $^{21}$.

En el caso particular del VIH, se debe tener en cuenta el conteo de linfocitos T-CD4+, puesto que, cuando se encuentra mayor a $500 \mathrm{cél} / \mathrm{mm}^{3}$ se debe considerar seroconversión aguda o etiologías similares al huésped inmunocompetente. Si está entre 200 y 500 cél $/ \mathrm{mm}^{3}$ se deben descartar infecciones bacterianas como Streptococcus pneumoniae, Haemophilus influenzae, Mycobacterium tuberculosis y virus de la familia herpesvirus como el VVZ. Si se encuentra por debajo de $200 \mathrm{cél} / \mathrm{mm}^{3}$, se deben sospechar infecciones oportunistas por cándida, Cryptococcus neoformans, VHS, VV y Toxoplasma gondii.22 En el caso del Virus de Inmunodeficiencia Humana (VIH) y otras infecciones relacionadas con síndrome meníngeo, es el VIH per se hasta una semana después de la infección primaria, además de histoplasmosis, aspergilosis, coccidioidomicosis, Candida albicans, Trypanosoma cruzii y Nocardia asteroides ${ }^{23}$.

Respecto al diagnóstico, los hallazgos clínicos son poco específicos, pues los mismos pueden estar presentes en otros tipos de meningitis. Por este motivo, el diagnóstico se realiza a través del examen de LCR con el hallazgo de pleocitosis, que suele ser linfocítica con un rango de 24 a $100 \%{ }^{16}$. La confirmación virológica dependía históricamente de la detección de anticuerpos o el aislamiento en el LCR para cultivo que normalmente requieren de un sustrato de células mamíferas, y especialmente varios tejidos como riñón de mono, neonatal o pulmón embrionario. Sin embargo, los cultivos han reportado una positividad que oscila de 6 al $91 \% 24$, el virus es lábil, el cultivo es lento, tiene poca sensibilidad y es costoso de realizar, por lo que este 
ha sido remplazado por técnicas moleculares de amplificación de ácidos nucleicos, como la Reacción en Cadena de la Polimerasa (PCR) y la detección de anticuerpos específicos contra VVZ en LCR. ${ }^{25}$ La PCR ha revolucionado la detección de patógenos virales y ha surgido como el estándar de oro, ${ }^{16}$ con una sensibilidad del 85 al $100 \%$ y una especificidad del 95 al $100 \%{ }^{17}$.

En cuanto al tratamiento, debe ser dirigido en contra del agente etiológico aislado durante el estudio. Sin embargo, en el enfoque inicial, el tratamiento debe ser empírico, buscando cubrir gérmenes gram positivos y gram negativos, conforme al perfil epidemiológico local $^{26}$, y en el caso particular del paciente inmunocomprometido, cubrimiento para VHS y otros agentes etiológicos acorde a los niveles de CD4, mientras llega el resultado de las pruebas moleculares y del estudio de LCR. Wright y cols. en una revisión de meningitis viral, confirman la poca evidencia existente en cuanto al uso de glucocorticoides en este contexto, por lo que no es una conducta recomendada, a diferencia de la meningitis bacteriana por Streptococcus Pneumoniae o Mycobacterium Tuberculosis, en donde ensayos clínicos aleatorizados apoyan su uso ${ }^{16}$.

El VVZ, por su parte, es morfológicamente similar a otros virus herpes y es clasificado como miembro Alphaherpesvirinae. Clásicamente está asociado con dos enfermedades distintas: varicela y herpes zóster. Su curso es usualmente dependiente de la edad y el estado inmunológico del paciente. En 1983 se reportaron títulos más bajos de anticuerpos contra VVZ en pacientes con síndrome de inmunodeficiencia adquirida (SIDA), comparados con pacientes sin SIDA $^{16}$. EI VVZ afecta alrededor del 20\% de la población general durante su vida, especialmente los ancianos, y entre el 8-11\% de pacientes con SIDA. No obstante, el riesgo relativo de infección por VVZ en individuos $\mathrm{VIH}$ seropositivos, es al menos 15 veces mayor que en los pacientes seronegativos ${ }^{27}$.

La reactivación del virus, es decir, su activación posterior a un estado de latencia, puede dar lugar a múltiples enfermedades y manifestaciones neurológicas, siendo la meningitis aséptica la de mejor pronóstico en este caso ${ }^{6}$. En el contexto de $\mathrm{VIH}$, se ha reportado una mortalidad cuando hay afección neurológica por VVZ del $12 \%{ }^{28}$. Normalmente, se consideraba al rash vesicular como un signo patognomónico en la sospecha clínica de éste agente infeccioso, sin embargo, se ha descrito hasta el $25 \%$ de casos con compromiso del sistema nervioso central en ausencia de éste?

La evolución natural de la infección primaria por VVZ es la latencia en más del $90 \%$ de la población, aunque la reactivación suele ocurrir en más del 50\% de los mayores de 85 años. Entre las manifestaciones producidas por el VVZ en el sistema nervioso central se encuentra la vasculopatía, manifestada como accidente cerebrovascular o aneurismas, y la cerebelitis, que se presenta con problemas de habla, nistagmus, cefalea y vómito ${ }^{29}$. En la mielopatía, típicamente se presenta con paraparesia espástica, y se ha descrito que el $54.8 \%$ de las series reportadas de mielitis por VVZ se relacionan con inmunocompromiso, predominantemente por $\mathrm{VIH}$, con resultados adversos y mayor mortalidad en los pacientes inmunocomprometidos, comparado con los inmunocompetentes, en quienes la terapia antiviral les permite obtener resultados favorables ${ }^{30}$.

Por su parte, la encefalitis y meningitis pueden coexistir juntas, así como ocurrir en conjunto con una vasculopatía y/o radiculitis. Se ha encontrado que el $39 \%$ de los pacientes en este grupo son inmunocomprometidos, con una mortalidad dentro del hospital, al mes y a los tres meses, de 4, 9 y $11 \%$ respectivamente. Además, los resultados adversos estuvieron presentes en un $69 \%$ de los casos $^{31}$.

Se describe un caso de meningitis aséptica por virus Varicela Zóster, en un paciente con infección por $\mathrm{VIH}$, sin la presencia de rash vesicular previo que guiara hacia el diagnóstico. Concomitante presentó hallazgo de FTA-ABS positivo en LCR, para lo cual se trató como sífilis reactivada dado el antecedente de tratamiento previo, buscando cumplir el principio ético de beneficencia.

\section{Presentación de caso}

Se trata de un paciente masculino de 31 años, procedente de la ciudad de Cali, que refiere como antecedentes personales sífilis latente tardía e infección por VIH, ambas diagnosticadas hacía 4 años, la primera tratada en ese tiempo con 3 dosis semanales de penicilina $G$ benzatínica. Para el VIH recibía tratamiento antirretroviral con poca continuidad por reacciones adversas e intolerancia a los medicamentos, actualmente con Darunavir $600 \mathrm{mg} /$ Ritonavir $100 \mathrm{mg} \times 2$ veces/día, 
Tenofovir+Emtricitabina 300/200 mg/día de forma regular desde hace aproximadamente 5 meses, con reporte de carga viral de 315 copias $/ \mathrm{mL}$, y los niveles de $\mathrm{CD} 4263 \mathrm{cel} / \mathrm{mm}^{3}$. Como antecedente ocupacional, se ha desempeñado como operario de metalmecánica desde hace varios años. Consultó por cuadro clínico de 3 días de evolución, consistente en cefalea holocraneana de intensidad severa, asociado a náuseas, emesis en tres ocasiones, fotofobia y pico febril cuantificado en $39^{\circ} \mathrm{C}$. Para esto había consumido únicamente acetaminofén, sin lograr controlar el dolor.

Al examen físico, paciente en aceptables condiciones generales, sin lesiones en piel, febril $\left(39.2^{\circ} \mathrm{C}\right)$, sin signos meníngeos, con resto de examen general y neurológico dentro de rangos de normalidad. Se toman paraclínicos de ingreso con serología en suero negativa, electrolitos y transaminasas normales, hemograma y proteína $C$ reactiva normal, función renal preservada, RMN de cerebro simple y contrastada normal y PL o punción lumbar, que muestra pleocitosis con predominio de polimorfonucleares, hiperproteinorraquia e hipoglucorraquia (relación glucosa LCR/sangre de 0.4 ), con ácido láctico en LCR por debajo de $4 \mathrm{mmol} / \mathrm{L}$ (2.55 mmol/L) y test de adenosín deaminasa (ADA) negativo (Ver Tabla 1).

El panel en LCR de encefalitis-meningitis por PCR FilmArray detectó el genoma del VVZ, por lo cual se inicia tratamiento con aciclovir intravenoso a la dosis de $10 \mathrm{mg} / \mathrm{kg} /$ día por 10 días. Al tercer día de tratamiento, el paciente presenta remisión total de sintomatología, sin embargo, llega reporte de prueba treponémica en LCR (FTA-ABS) positiva, indicándose, además, manejo con penicilina cristalina por 14 días, tratamiento que se indicó por principio de beneficencia, al sospechar reactivación de la sífilis. El paciente completa manejo intrahospitalario sin complicaciones, y se da de alta asintomático. La figura 1 muestra la línea de tiempo de la hospitalización. (ver Figura 1)

\section{Discusión}

La meningitis aséptica constituye un diagnóstico con múltiples etiologías. El diagnóstico diferencial cuando nos enfrentamos en urgencias, es distinguirla con meningitis bacteriana, en la cual se encuentra predominancia de neutrófilos en LCR, hipoglucorraquia, y presencia de bacterias en el cultivo o gram ${ }^{3}$. Las consideraciones epidemiológicas y hallazgos clínicos ayudan a distinguir entre leptospira, enfermedad de Lyme, y meningitis sifilítica, mientras que la hipoglucorraquia sugiere desde lo infeccioso tuberculosis y meningitis criptocóccica, y en las no infecciosas indica malignidad o sarcoidosis ${ }^{17}$.

Tabla 1. Resultados del análisis del líquido cefalorraquídeo

\begin{tabular}{|c|c|c|}
\hline \multicolumn{3}{|c|}{$\begin{array}{c}\text { Análisis físico } \\
\text { Presión de apertura } 25 \mathrm{cmH} 20\end{array}$} \\
\hline PARÁMETRO & RESULTADO & $\begin{array}{c}\text { VALOR } \\
\text { NORMAL } \\
\end{array}$ \\
\hline Aspecto & Transparente & Transparente \\
\hline Glucosa & $\begin{array}{c}48 \mathrm{mg} / \mathrm{dl} \text { (en sangre: } \\
118 \mathrm{mg} / \mathrm{dL} \text { ) }\end{array}$ & \\
\hline Proteínas & $102.9 \mathrm{mg} / \mathrm{dl}$ & $15-45 \mathrm{mg} / \mathrm{dl}$ \\
\hline \multicolumn{3}{|c|}{ Recuento celular } \\
\hline Leucocitos & 48 células $/ \mathrm{mm} 3$ & 0-5 células $/ \mathrm{mm} 3$ \\
\hline Polimorfonucleares & $80 \%$ & 0 \\
\hline Mononucleares & $20 \%$ & $100 \%$ \\
\hline Eritrocitos & 15 células $/ \mathrm{mm} 3$ & 0 células $/ \mathrm{mm} 3$ \\
\hline Frescos & $100 \%$ & 0 \\
\hline \multicolumn{3}{|c|}{ Tinciones y otros } \\
\hline $\begin{array}{l}\text { Coloración de } \\
\text { GRAM }\end{array}$ & Negativo & Negativo \\
\hline $\begin{array}{l}\text { Coloración de Tinta } \\
\text { china }\end{array}$ & Negativo & Negativo \\
\hline $\begin{array}{l}\text { Antígeno para } \\
\text { Cryptococo por } \\
\text { Látex }\end{array}$ & No reactivo & No reactivo \\
\hline VDRL & No reactivo & No reactivo \\
\hline $\begin{array}{l}\text { PCR para } \\
\text { Mycobacterium } \\
\text { tuberculosis }\end{array}$ & No detectable & No detectable \\
\hline Test de ADA & $2 \mathrm{U} / \mathrm{L}$ & $0-5 \mathrm{U} / \mathrm{L}$ \\
\hline Lactato & $\begin{array}{c}23.3 \mathrm{mg} / \mathrm{dL}(2.55 \\
\mathrm{mmol} / \mathrm{L})\end{array}$ & $10-22 \mathrm{mg} / \mathrm{dL}$ \\
\hline PCR FilmArray & $\begin{array}{c}\text { Detectado varicela } \\
\text { zóster }\end{array}$ & \\
\hline FTA-ABS & Reactivo & No reactivo \\
\hline
\end{tabular}

Fuente: autores

En el LCR, la pleocitosis es un marcador sensible para inflamación meníngea, tal como se observó en nuestro paciente, quien tenía pleocitosis con predominio polimorfonucleares hiperproteinorraquia y consumo de glucosa, lo cual sugiere infección bacteriana, aunque los cultivos de microorganismos y tinción de gram fueron negativos sin tener previamente 
inicio de tratamiento antibiótico. No obstante, la presentación clínica no era sugestiva de infección bacteriana, ya que, aunque son pocos los estudios publicados en este área, se ha encontrado que la presencia de tan sólo un signo de severidad entre los siguientes: alteración de la conciencia, crisis convulsivas, hallazgos neurológicos focales y choque; tiene una sensibilidad (S) de 99\%, especificidad (E) de 98\%, Valor Predictivo Positivo (VPP) de $99 \%$ y Valor Predictivo Negativo (VPN) de $98 \%$ como predictor de meningitis bacteriana. ${ }^{32}$

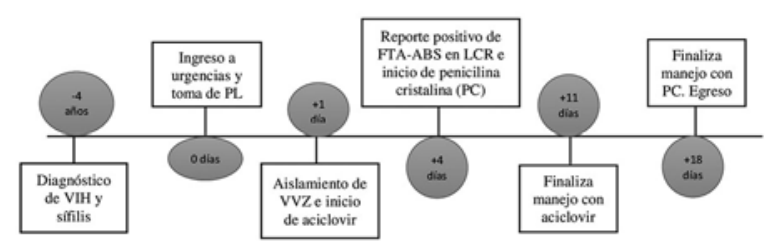

Figura 1. Línea del tiempo de hospitalización

Fuente: autores

Aunque durante las dos últimas décadas, nuevas herramientas han mejorado el rendimiento del diagnóstico microbiológico, incluyendo $P C R$, única o múltiple; la etiología, sin embargo, permanece desconocida en hasta dos tercios de los casos de meningitis aséptica, incluso en las series más recientes, a pesar de un enfoque diagnóstico exhaustivo ${ }^{21}$. No obstante, se considera que la distinción más importante radica en diferenciar meningitis aséptica de bacteriana ${ }^{33}$.

Más recientemente, se han utilizado exámenes de laboratorio como marcadores que pueden diferenciar entre meningitis bacteriana de aséptica. Entre éstos se encuentra el ácido láctico, que en el caso de nuestro paciente se encontraba en $2.55 \mathrm{mmol} / \mathrm{L}$. Se ha establecido que un corte mayor a $4 \mathrm{mmol} / \mathrm{L}$ tiene una $\mathrm{S}=91 \%, \mathrm{E}=92 \%$, VPP= $89 \%$ y $\mathrm{VPN}=93 \%$ para definir meningitis bacteriana ${ }^{34}$.

Ante la sospecha de meningitis bacteriana se debe iniciar manejo antibiótico sin retraso considerando que la mortalidad incrementa $12.6 \%$ por cada hora de retraso ${ }^{35}$. Viallon et al., propusieron un algoritmo de manejo de la meningitis que se ha adaptado en la figura $2^{36}$. Al realizarse cada uno de los pasos en el presente caso, se consideró que no era necesario el inicio de antibiótico dado que no presentó púrpura, sepsis severa/choque séptico, déficit neurológico focal o nueva convulsión; así como la ausencia de hallazgos macroscópicos de purulencia del esputo, gram negativo para bacterias, y niveles de lactato normales ${ }^{36}$ (Ver Figura 2).

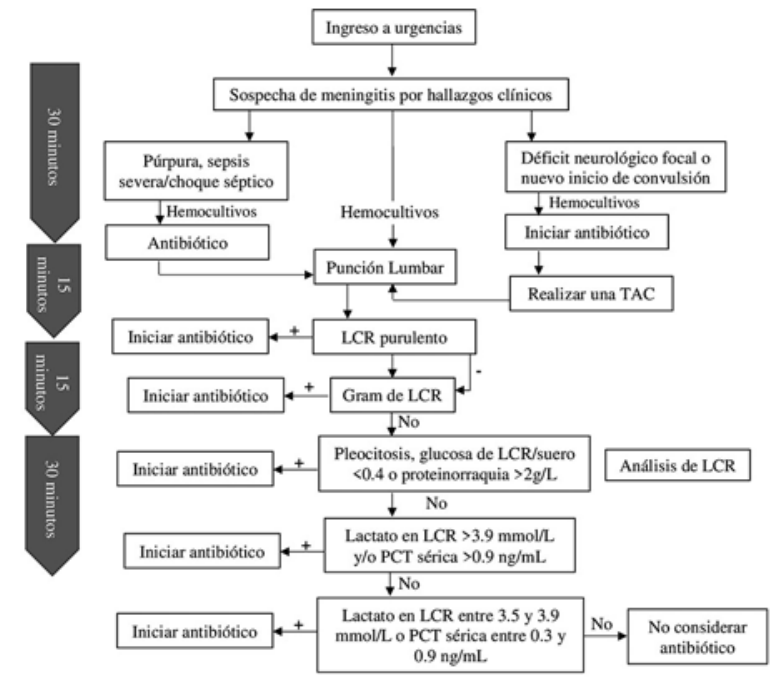

Figura 2. Algoritmo de manejo de meningitis adaptado de Viallon et al. ${ }^{36}$

Fuente: Adaptado de: Viallon A, Botelho-Nevers E, Zeni F. Clinical decision rules for acute bacterial meningitis: current insights. Open Access Emerg Med. 2016;8:7-16

Las recomendaciones de realizar una neuroimagen previa a la punción lumbar, ha sido abordada por múltiples guías; entre las que destaca la Infectious Diseases Society of America (IDSA) ${ }^{37}$ y la European Society of Clinical Microbiology and Infectious Diseases (ESCMID) ${ }^{38}$, ambas con múltiples criterios, entre los que se encuentra la infección por VIH, como el caso de nuestro paciente. Glimaker $M$. et al. 39 desarrollaron una guía en la que únicamente se toma en consideración el estado mental alterado con signos de herniación cerebral y déficit neurológico focal. Considerando que en muchas ocasiones se solicita neuroimagen previa a la punción lumbar sin ser requerida, lo cual se traduce en aumento de mortalidad por retraso en la toma de conductas apropiadas, se demostró que, comparada con las guías desarrolladas por las otras dos sociedades, ésta impactó positivamente la mortalidad y mejoró los resultados clínicos ${ }^{40}$.

El típico rash segmentario usualmente permite un rápido diagnóstico clínico. No obstante, si el exantema está ausente, el diagnóstico se puede retrasar con las complicaciones que esto implica en pacientes con infección a nivel del sistema nervioso central $^{6}$. En este sentido, se demuestra la importancia de las pruebas moleculares que en el caso de nuestro paciente, permitieron realizar el diagnóstico de meningitis por Varicella Zóster a pesar de la ausencia 
de erupción vesicular, hallazgo característico ante una reactivación viral, aunque ha demostrado que tiene una baja sensibilidad con ausencia en más de un tercio de los casos de infección en sistema nervioso centrals.

Corti M. et al. reportaron once casos de meningoencefalitis debido a VVZ en pacientes con infección por VIH. La edad promedio de los casos fue de 34.7 años, muy similar al caso actual. En cuanto a la sintomatología, el $63.6 \%$ tuvo ausencia de signos meníngeos y presencia de fiebre; el 91\% ausencia de convulsiones, el $82 \%$ presentó cefalea, $27.3 \%$ ausencia de lesiones mucocutáneas concomitantes, el $63.6 \%$ ausencia de signos neurológicos focales tal como el caso actual. En el 100\% de los casos se realizó el diagnóstico por PCR y el $36.4 \%$ de los casos tuvo un desenlace fatal. A diferencia de nuestro paciente, el nivel promedio de CD4 fue de 142 células $/ \mathrm{mL}^{41}$.

Las plataformas multiplex de diagnóstico molecular han tomado gran relevancia en la práctica clínica actual. En nuestro paciente se realizó el panel FilmArray meningitis/encefalitis (BioFire Diagnostics, Salt Lake City, UT), el cual es un sistema de PCR multiplex que permite detectar catorce patógenos en aproximadamente una hora, entre los que se incluye el virus varicela zóster, con una sensibilidad para este agente de $100 \%$ y especificidad del $99.8 \%{ }^{42-43}$, así como otros patógenos, tanto bacterianos, virales y fúngicos, que constituyen etiologías causales de la meningitis aséptica y que pueden potencialmente cambiar el tratamiento instaurado. Cabe destacar que, a pesar de que el predominio de polimorfonucleares es muy sugestivo de meningitis bacteriana, en las primeras 6 a 48 horas el LCR en la meningitis viral puede tener este patrón ${ }^{44}$.

El diagnóstico de la infección del SNC por VZV también podría realizarse mediante la determinación de la producción intratecal de anticuerpos contra VZV. Se calcula la relación entre títulos de IgG LCR/ suero contra el VZV medidos mediante un ensayo inmunoabsorbente ligado a enzimas (ELISA). Los análisis serológicos de anticuerpos intratecales son usados principalmente cuando la PCR es negativa, lo cual no es infrecuente, y puede ser el resultado de un diagnóstico tardío o en el escenario de una vasculopatía del SNC secundaria a VZV45,46.

Por otra parte, el paciente, aparte del antecedente de infección por VIH, tuvo una sífilis latente tratada, con serología no reactiva posterior. Al ingreso se repitieron VDRL tanto en suero como en $L C R$ siendo no reactivos, con FTA-ABS en LCR reactivo. Actualmente, no existe estándar de oro para el diagnóstico de neurosífilis y entre las diferentes pruebas existentes, se ha encontrado una sensibilidad y especificidad variable acorde al estadío de la misma. Los estadios que se han planteado en neurosífilis son: temprano que incluye la neurosífilis asintomática temprana y meningitis sifilítica; temprana o tardía en donde se encuentra la sífilis meningovascular; y finalmente la tardía con la parálisis general y tabes dorsal47. En la sífilis temprana la sensibilidad de la serología VDRL y RPR en sangre es del $100 \%$ y en LCR $75 \%$; en cambio el FTA-ABS tiene una $S=100 \%$ tanto en sangre como en LCR. No obstante, éstos valores se ven disminuidos en la neurosífilis sintomática tardía con una sensibilidad del VDRL y RPR en sangre de 50-75\% y en LCR de 30$70 \%$ sin verse mayormente afectado el FTA-ABS con una sensibilidad aproximada en sangre de $96 \%$ y en LCR de 99\%. No es así la especificidad, la cual es del $100 \%$ para VDRL de LCR si no está contaminado con sangre y de aproximadamente $50-70 \%$ para FTA-ABS en $L C R^{47}$.

Se han planteado como criterios diagnósticos confirmatorios cuando hay VDRL reactivo en suero, independiente de la presencia de síntomas o signos de neurosífilis y en LCR reactividad del VDRL; o es presuntivo cuando hay pleocitosis $(>l=5$ células) o hiperproteinorraquia $(>/=45 \mathrm{mg} / \mathrm{dL})$ en el $L C R$ en ausencia de reactividad del VDRL en LCR sin un diagnóstico alternativo. Esto es debido a lo que se especificó anteriormente, y es que el VDRL es altamente específico en LCR, pero poco sensible, pudiendo ser negativo en $30-70 \%$ de los casos; al mismo tiempo, el FTA-ABS es altamente sensible pero no específico, siendo razonable para descartar neurosífilis cuando es negativo. Por esta razón, los CDC (Centros para el control de enfermedades de Estados Unidos) no recomiendan las pruebas treponémicas en LCR pues un resultado positivo puede no reflejar neurosífilis ${ }^{48}$.

El caso del paciente tuvo unas particularidades que descartaban el diagnóstico de neurosífilis. En primera instancia, el aislamiento microbiológico de VVZ en LCR; en segundo lugar, la resolución completa de los síntomas con el tratamiento con aciclovir; tercero la presencia de hematíes frescos en la muestra de LCR que podrían generar un resultado falso positivo, y en cuarto lugar, que no cumplía los criterios diagnósticos para neurosífilis. Pese a lo anterior, se consideró tratar al paciente como si tuviese una 
neurosífilis, dado su estado de inmunocompromiso, el riesgo descrito tres veces mayor de afectación neurológica por sífilis en pacientes con infección por VIH con CD4 menor a 350 células $^{49}$ como nuestro paciente, más considerando su pobre adherencia a la medicación antirretroviral. Se consideró entonces que dar el tratamiento tenía más beneficios que riesgos, y cumplía con el principio de beneficencia y no-maleficencia.

\section{Conclusiones}

La meningitis constituye una emergencia médica que se debe sospechar y tratar para evitar un desenlace fatal. En el caso del paciente con infección por VIH, se deben considerar otras etiologías diagnósticas que a menudo no pueden ser diagnosticadas con los métodos convencionales. Por este motivo, las nuevas técnicas diagnósticas como el FilmArray, que es altamente sensible y específico, permiten mejorar la precisión en la actuación, evitan dar tratamientos empíricos que aumentan la resistencia a los antimicrobianos y pueden tener efectos adversos, y coadyuvan a mejorar los resultados. La infección del SNC por VVZ constituye un espectro de enfermedades que va desde vasculopatía, manifestada como accidente cerebrovascular, hasta la meningitis, que constituye la patología de mejor pronóstico en este contexto. No obstante, en el paciente inmunocomprometido suele generar resultados adversos y poco favorables cuando se compara con el inmunocompetente. Es por esto que se debe sospechar, independientemente de la presencia de rash vesicular, que se encuentra ausente en más de un tercio de quienes presentan infección en SNC.

\section{Referencias bibliográficas}

1. McGill F, Griffiths MJ, Solomon T. Viral meningitis: current issues in diagnosis and treatment. Curr Opin Infect Dis. 2017;30(2):248-56.

2. Aguirre C, Vallejo I, Vargas A, Acevedo L, Uribe G, Londoño A. Epidemia de meningitis viral en Medellín, Colombia, 2004. Rev. salud pública. 2006;1(1):67-82.

3. Shukla B, Aguilera EA, Salazar L, Wootton SH, Kaewpoowat Q, Hasbun R. Aseptic meningitis in adults and children: Diagnostic and management challenges. J Clin Virol. 2017;94:110-4.

4. Gilden D, Cohrs RJ, Mahalingam R, Nagel MA. Neurological disease produced by varicella zoster virus reactivation without rash. Curr Top Microbiol Immunol. 2010;342: 243-53.

5. Becerra JC, Sieber R, Martinetti G, Costa ST, Meylan P, Bernasconi E. Infection of the central nervous system caused by varicella zoster virus reactivation: a retrospective case series study. Int J Infect Dis. 2013;17(7):e529-34.

6. Skripuletz T, Pars K, Schulte A, Schwenkenbecher P, Yildiz Ö, Ganzenmueller T, et al. Varicella zoster virus infections in neurological patients: a clinical study. BMC Infect Dis. 2018;18(1):238.
7. Pasedag T, Weissenborn K, Wurster U, Ganzenmueller T, Stangel M, Skripuletz T. Varicella zoster virus meningitis in a young immunocompetent adult without rash: a misleading clinical presentation. Case Rep Neurol Med. 2014;2014:1-4.

8. Arrut M, Piñeiro LD, Salicio Y, Cilla G, Goenaga MA, López A. Incidence of varicella zoster virus infections of the central nervous system in the elderly: a large tertiary hospital-based series (2007-2014). J Neurovirol. 2017;23(3):451-9.

9. Pormohammad A, Goudarzi H, Eslami G, Falah F, Taheri F Ghadiri N, et al. Epidemiology of herpes simplex and varicella zoster virus in cerebrospinal fluid of patients suffering from meningitis in Iran. New Microbes New Infect. 2020;36(C):1-6.

10. Tique V, Alvis N, Parodi R, Bustos A, Mattar S. Meningitis aguda en Córdoba, Colombia, 2002-2004. Rev. Salud Pública. 2006;8(1):33-44.

11. Morales A, Alonso LM. Epidemiología de la meningitis una visión socio-epidemiológica. Salud Uninorte. 2006;22(2):105-20.

12. Hersi K, Gonzalez FJ, Kondamudi NP. Meningitis. [Monografia en Internet]. Treasure Island (FL): StatPearls Publishing; 2020 [Citado 23 Mayo 2020]. Disponible en: https://www.ncbi.nlm. nih.gov/books/NBK459360/\#

13. Marin M, Harpaz R, Zhang J, Wollan PC, Bialek SR, Yawn BP. Risk Factors for Herpes Zoster among adults. Open Forum Infect Dis. 2016; 3(3)

14. Marra F, Parhar K, Huang B, Vadlamudi N. Risk factors for herpes zoster infection: A meta-analysis. Open Forum Infect Dis. 2020; $7(1)$

15. Kim SH, Choi SM, Choi KH, Nam TS, Kim JT, Lee SH, et al. Risk factors for aseptic meningitis in herpes Zoster patients. Ann Dermatol 2017;29(3):283-7.

16. Wright WF, Pinto CN, Palisoc K, Baghli S. Viral (Aseptic) Meningitis: A Review. J Neurol Sci. 2019;398:176-83.

17. Swartz MN, Nath. Goldman's Cecil Medicine. New York: Elsevier Inc; 2020.

18. Gupta P, Ranjan R, Agrawal CS, Muralikrishan K, Dave N, Rana DS. Meningitis with polymerase chain reaction for varicella zoster positivity in cerebrospinal fluid of a young immunocompetent adult. J Neurosci Rural Pract. 2016;7(4):591-3.

19. Fang M, Weng X, Chen L, Chen Y, Chi Y, Chen W., et al. Fulminant central nervous system varicella-zoster virus infection unexpectedly diagnosed by metagenomic next-generation sequencing in an HIV-infected patient: a case report. BMC infect Dis. 2020; 20(1):159.

20. O'Sullivan CE, Aksamit AJ, Harrington JR, Harmsen WS, Mitchell PS, Patel R. Clinical spectrum and laboratory characteristics associated with detection of herpes simplex virus DNA in cerebrospinal fluid. Mayo Clin Proc. 2003;78(11):1347-52.

21. Tattevin P, Tchamgoué S, Belem A, Bénézit F, Pronier C, Revest M. Aseptic Meningitis. Rev Neurol. 2019;175(7-8):475-80.

22. Florence E, Bottieau E, Lynen L, Colebunders R. Patients with HIV infection and fever: a diagnostic approach. Acta Clin. Belg. 2002;57(4):184-90.

23. Siddiqi OK, Koralnik IJ. Principles and Practice of Infectious Diseases. New York. Elsevier Inc; 2015.

24. Kupila L, Vuorinen T, Vainionpää R, Hukkanen V, Marttila RJ, Kotilainen P. Etiology of Aseptic meningitis and encephalitis in an adult population. Neurology. 2006;66(1):75-80.

25. Baldwin KJ, Cummings CL. Herpesvirus Infections of the Nervous System. Minneap Minn. 2018;24(5):1349-1369.

26. Brouwer MC, Van de Beek D. Management of bacterial central nervous system infections. Handb Clin Neurol. 2017;140:349-64.

27. Vafai A, Berger M. Zoster in patients infected with HIV: a review. Am J Med Sci. 2001;321(6):372-80.

28. Frías-Salcedo JA. Experiencia clínica de la asociación entre Zóster y SIDA en los últimos 10 años en el servicio de infectología de adultos del hospital central Militar. Rev Sanid Milit Mex. 2003;57(2):45-51.

29. Nagel MA, Niemeyer CS, Bubak A. Central nervous system infections produced by varicella Zoster virus. Curr Opin Infect Dis. 2020;33(3):273-78.

30. Hung $\mathrm{CH}$, Chang KH, Kuo HC, Huang CC, Liao MF, Tsai YT, et al. Features of varicella zoster virus myelitis and dependence on immune status. J Neurol Sci. 2012;318(1-2):19-24.

31. Herlin LK, Hansen KS, Bodilsen J, Larse L, Brandt C, Andersen $\mathrm{CO}$, et al. Varicella zoster virus encephalitis in Denmark from 
2015 to 2019 - A nationwide prospective cohort study. Clin Infect Dis. 2020;72(7):1192-9

32. Brivet F, Ducuing S, Jacobs F, Chary I, Pompier R, Prat D, et al. Accuracy of Clinicas Presentation for Differentiating Bacterial From Viral Meningitis in Adults: A multivariate Approach. Intensive Care Med. 2005;31(12):1654-60.

33. Bahr NC, Boulware DR. Methods of rapid diagnosis for the etiology of meningitis in adults. Biomark Med. 2014;8(9):1085-103.

34. Celis A, Ospina S, Becerra G. Utilidad del lactato en líquido cefalorraquídeo como biomarcador de meningitis bacteriana. Infectio. 2018;22(2):64-9.

35. Glimaker M, Johansson B, Grindborg Ö, Bottai M, Lindquist L, Sjölin J. Adult Bacterial Meningitis: Earlier treatment and improved outcome following guideline revision promoting prompt lumbar puncture. Clin Infect Dis. 2015;60(8):1162-9.

36. Viallon A, Botelho E, Zeni F. Clinical decision rules for acute bacterial meningitis: current insights. Open Acces Emerg Med. 2016; 8: 7-16. Disponible en: https://doi.org/10.2147/OAEM. S69975

37. Tunkel AR, Hartman BJ, Kaplan SL, Kaufman BA, Roos KL, Scheld WM, et al. Practice guidelines for the management of bacterial meningitis. Clin Infect Dis. 2004;39(9):1267-84.

38. Van de Beek D, Cabellos C, Dzupova O, Esposito S, Klein M, Kloek AT, et al. ESCMID guideline: diagnosis and treatment of acute bacterial meningitis. Clin Microbiol Infect 2016; 22(3):37-62.

39. Glimåker M, Johansson B, Bell $M$, Ericsson $M$, Bläckberg J, Brink M, et al. Early lumbar puncture in adult bacterial meningitis-rationale for revised guidelines. Scand J Infect Dis. 2013;45(9):657-63.

40. Glimaker M, Sjölin J, Akesson S, Naucler P. Lumbar puncture performed promptly or after neuroimaging in acute bacterial meningitis in adults: a prospective national cohort study positivo. Presentación de caso

evaluating different guidelines. Clin Infect Dis. 2018;66(3):321-28.

41. Corti $M$, Villafañe $M F$, Vittar $N$, Banco $M C$, Priarone $M$, Mammana L, et al. Meningoencephalitis due to varicella zoster virus in AIDS patients. Report of eleven cases and review of the literature. Rev Inst Med Trop S Paulo. 2015;57(6):505-8.

42. Leber AL, Everhart K, Balada-Llasat JM, Cullison J, Daly J, Holt S, et al. Multicenter Evaluation of BioFire FilmArray Meningitis/Encephalitis Panel for Detection of Bacteria, Viruses, and Yeast in Cerebrospinal Fluid Specimens. J Clin Microbiol. 2016;54(9):2251-61.

43. Eichinger A, Hagen A, Meyer-Bühn M, Huebner J. Clinical benefits of introducing real-time multiplex PCR for cerebrospinal fluid as routine diagnostic at a tertiary care pediatric center. Infection. 2019;47(1):51-8.

44. Jaijakul S, Salazar L, Wootton SH, Aguilera E, Hasbun R. The clinical significance of neutrophilic pleocytosis in cerebrospinal fluid in patients with viral central nervous system infections. Int J Infect Dis. 2017;59:77-81.

45. Gregoire SM, Van Pesch V, Goffette S, Peeters A, Sindic CJ. Polymerase chain reaction analysis and oligoclonal antibody in the cerebrospinal fluid from 34 patients with varicella-zoster virus infection of the nervous system. J Neurol Neurosurg Psychiatry. 2006; 77(8):938-42.

46. Grahn A, Studahl M. Varicella-zoster virus infections of the central nervous system - prognosis, diagnostics and treatment. J Infect. 2015;71(3):281-93.

47. Ropper A. Neurosyphilis. N Engl J Med. 2019;381:1358-63.

48. Ghanem KG. REVIEW: Neurosyphilis: A historical perspective and review. CNS Neurosci Ther. 2010;16(5):157-68.

49. Hobbs E, Vera JH, Marks M, Barrit AW, Ridha BH, Lawrence D. Neurosyphilis in patients with HIV. Pract Neurol. 2018;18(3):211218. 